\title{
In situ Growth of Gold Nanoparticles Based on Simultaneous Green Reduction by Methylene Blue for Non-Enzymatic Glucose Sensing
}

\author{
Wenyuan Zhu ${ }^{l}$, Xiaoya $\mathrm{Li}^{1}$, Weihong Liu ${ }^{1}$, Zuodong Chen ${ }^{1}$, Jianping $\mathrm{Li}^{1}$ and Hongcheng Pan ${ }^{1,2,3, *}$ \\ ${ }^{1}$ College of Chemistry and Bioengineering, Guilin University of Technology, 12 Jiangan Road, Guilin \\ 541004, P. R. China. \\ ${ }^{2}$ Guangxi Colleges and Universities Key Laboratory of Food Safety and Detection, Guilin University \\ of Technology, 12 Jiangan Road, Guilin 541004, P. R. China. \\ ${ }^{3}$ Guangxi Key Laboratory of Electrochemistry and Magnetiochemistry Functional Materials, Guilin \\ University of Technology, 12 Jiangan Road, Guilin 541004, P. R. China. \\ *E-mail: $\underline{\text { hcpan@163.com }}$
}

doi: $10.20964 / 2017.06 .23$

Received: 23 February 2017 / Accepted: 5 April 2017 / Published: 12 May 2017

\begin{abstract}
We presents a novel approach for in situ growth of highly-dispersed gold nanoparticles (AuNPs) on the electropolymerized methylene blue (PMB)/ITO electrode (Au/PMB/ITO) without using additional binding molecules and toxic reductants. Methylene blue (MB) monomers remaining in the PMB films on ITO served as both the reductant to form AuNPs by reducing $\mathrm{AuCl}^{4-}$, and as anchoring sites for in situ growth of AuNPs via the electrostatic interaction between $\mathrm{AuCl}^{4-}$ and positively charged $\mathrm{MB}$ that avoids the aggregation of AuNPs, thereby improving their dispersity. Cyclic voltammetry (CV), differential pulse voltammetry (DPV), scanning electron microscope (SEM), UV-Vis spectroscopy (UV-Vis) and Fourier transformation infrared spectroscopy (FTIR) were used to characterize the resulting polymer and nanoparticles. The as-prepared Au/PMB/ITO exhibited an excellent electrocatalytic activity towards glucose oxidation with a high sensitivity of $312 \mu \mathrm{A} \mathrm{mM} \mathrm{mm}^{-1} \mathrm{~cm}^{-2}$ at a low operating potential of $0.04 \mathrm{~V}$.
\end{abstract}

Keywords: Gold Nanoparticles; In Situ Growth; Methylene blue; non-enzymatic glucose sensing

\section{$\underline{\text { FULL TEXT }}$}

(C) 2017 The Authors. Published by ESG (www.electrochemsci.org). This article is an open access article distributed under the terms and conditions of the Creative Commons Attribution license (http://creativecommons.org/licenses/by/4.0/). 